\title{
The Vanilloid Receptor TRPV1 Is Tonically Activated In Vivo and Involved in Body Temperature Regulation
}

\author{
Narender R. Gavva, ${ }^{1}$ Anthony W. Bannon, ${ }^{1}$ Sekhar Surapaneni, ${ }^{2}$ David N. Hovland Jr, ${ }^{3}$ Sonya G. Lehto, ${ }^{1}$ Anu Gore, ${ }^{4}$ \\ Todd Juan, ${ }^{5}$ Hong Deng, ${ }^{1}$ Bora Han, ${ }^{3}$ Lana Klionsky, ${ }^{1}$ Rongzhen Kuang, ${ }^{1}$ April Le, ${ }^{1}$ Rami Tamir, ${ }^{1}$ Jue Wang, ${ }^{1}$ \\ Brad Youngblood, ${ }^{1}$ Dawn Zhu, ${ }^{1}$ Mark H. Norman, ${ }^{6}$ Ella Magal, ${ }^{1}$ James J. S. Treanor, ${ }^{1}$ and Jean-Claude Louis ${ }^{1}$ \\ Departments of ${ }^{1}$ Neuroscience, ${ }^{2}$ Pharmacokinetics and Drug Metabolism, ${ }^{3}$ Toxicology, ${ }^{4}$ Pharmaceutics, ${ }^{5}$ Protein Sciences, and ${ }^{6} \mathrm{Chemistry}$ Research and \\ Discovery, Amgen, Thousand Oaks, California 91320-1799
}

The vanilloid receptor TRPV1 (transient receptor potential vanilloid 1) is a cation channel that serves as a polymodal detector of pain-producing stimuli such as capsaicin, protons $(\mathrm{pH}<5.7)$, and heat. TRPV1 antagonists block pain behaviors in rodent models of inflammatory, neuropathic, and cancer pain, suggesting their utility as analgesics. Here, we report that TRPV1 antagonists representing various chemotypes cause an increase in body temperature (hyperthermia), identifying a potential issue for their clinical development. Peripheral restriction of antagonists did not eliminate hyperthermia, suggesting that the site of action is predominantly outside of the blood-brain barrier. Antagonists that are ineffective against proton activation also caused hyperthermia, indicating that blocking capsaicin and heat activation of TRPV1 is sufficient to produce hyperthermia. All TRPV1 antagonists evaluated here caused hyperthermia, suggesting that TRPV1 is tonically activated in vivo and that TRPV1 antagonism and hyperthermia are not separable. TRPV1 antagonists caused hyperthermia in multiple species (rats, dogs, and monkeys), demonstrating that TRPV1 function in thermoregulation is conserved from rodents to primates. Together, these results indicate that tonic TRPV1 activation regulates body temperature.

Key words: antagonist; calcium channels; capsaicin; hyperthermia; pain; TRPV

\section{Introduction}

Members of the transient receptor potential (TRP) ion channel superfamily are proposed to mediate various sensory functions such as touch, pain, taste, and thermosensation (Clapham, 2003). TRP vanilloid (TRPV1-4) and melastatin (TRPM8) family members and TRP ankyrin 1 (TRPA1) are directly activated by either heat or cold and by compounds that modulate sensations of warmth, cooling, and burning pain (Caterina et al., 1997; Jordt et al., 2003; Patapoutian et al., 2003; Dhaka et al., 2006). Capsaicin, the active ingredient of hot chili peppers, and its ultrapotent vanilloid analog, resiniferatoxin (RTX), from Euphorbia resinifera, elicit burning pain by activating TRPV1 channels on sensory nerve endings (Caterina et al., 1997; Szallasi and Blumberg, 1999). In addition to capsaicin and RTX, multiple other ligands [anandamide, protons ( $\mathrm{pH}<5.7)$, and products of lipoxygenase], heat $\left(>42^{\circ} \mathrm{C}\right)$, and G-protein-coupled receptor signaling activate TRPV1, making it a molecular integrator of multiple noxious stimuli (Caterina et al., 1997; Tominaga et al., 1998; Szallasi and Blumberg, 1999; Holzer, 2004; Szolcsanyi, 2004). TRPV1 emerged as a therapeutic target for pain because (1) agonists of TRPV1 cause desensitization of the channel and subse-

Received Nov. 7, 2006; revised Jan. 16, 2007; accepted Feb. 7, 2007.

We thank Chris Fibiger for support and Dirk Beher, Bart Manning, and Ken Wild for helpful comments and critical reading of this manuscript. All authors are employed by Amgen.

Correspondence should be addressed to Dr. Narender R. Gavva, Department of Neuroscience, Amgen, One Amgen Center Drive, Thousand 0aks, CA 91320-1799. E-mail:ngavva@amgen.com.

D01:10.1523/JNEUROSCI.4833-06.2007

Copyright $\odot 2007$ Society for Neuroscience $\quad$ 0270-6474/07/273366-09\$15.00/0 quent neuronal ablation, which alleviate pain-like behaviors in rodents and pain in humans (Szallasi and Blumberg, 1999), (2) it is upregulated during inflammatory conditions and is activated by components of the "inflammatory soup" to transduce inflammation-induced hyperalgesia in rats (Ji et al., 2002; Holzer, 2004; Szolcsanyi, 2004; Keeble et al., 2005), and (3) TRPV1 knock-out mice display reduced thermal hypersensitivity after inflammatory tissue injury (Caterina et al., 2000; Davis et al., 2000).

Several novel TRPV1 antagonists were discovered by high throughput screening of chemical libraries and by medicinal chemistry efforts (Valenzano et al., 2003; Szallasi and Appendino, 2004; Doherty et al., 2005; El Kouhen et al., 2005; Gavva et al., 2005a,b; Swanson et al., 2005; Xi et al., 2005; Ognyanov et al., 2006) that block all modes of activation and produce antihyperalgesic effects in models of inflammatory (Pomonis et al., 2003; Gavva et al., 2005b; Honore et al., 2005; and references therein) and surgical-incision pain (Honore et al., 2005), as well as analgesia in cancer pain models (Ghilardi et al., 2005), confirming the potential utility of TRPV1 antagonists as therapeutics for pain.

Agonists of TRPV1, such as capsaicin and RTX, have long been known to decrease body temperature (producing hypothermia) in multiple species, including humans (Hori, 1984; Szallasi and Blumberg, 1999). However, it is not known whether TRPV1 is tonically activated in naive rodents and primates, or even whether it is involved in body temperature regulation. In our efforts to evaluate on-target coverage (antagonism) of TRPV1 in vivo, we tested the ability of TRPV1 antagonists to block 
capsaicin-induced hypothermia. TRPV1 antagonists, such as (E)-3-(4-t-butylphenyl)-N-(2,3-dihydrobenzo[b] [1,4] dioxin6-yl)acrylamide (AMG9810), not only blocked capsaicininduced hypothermia in rats but also caused hyperthermia on their own. Here, we describe investigations of the pharmacology and brain-penetration properties of TRPV1 antagonists that revealed the presence of tonic TRPV1 activation in vivo and body temperature regulation as its primary function.

\section{Materials and Methods}

Cloning, cell lines, and ${ }^{45} \mathrm{Ca}^{2+}$ uptake assays. Cloning and stable cell generation for rat and human TRPV1 was described by Gavva et al. (2004). Chinese hamster ovary $(\mathrm{CHO})$ cells stably expressing rat TRPV1 were maintained in DMEM supplemented with $10 \%$ dialyzed FBS, $800 \mu \mathrm{g} / \mathrm{ml}$ Genetecin, penicillin, streptomycin, L-glutamine, and nonessential amino acids. RNA from cynomolgus monkey DRG was prepared and used for generating first-strand cDNA using a cDNA synthesis kit (BD Clontech, Palo Alto, CA). Two primers, 5'-GGCTCTATGATCGCAGGATATC-3' and 5'-CTCTGCTTGACCGCAGGGAG-3', were used in a PCR to amplify the partial cynomolgus monkey cDNA. The PCR product was then subcloned into a pcDNA3.1 vector (Invitrogen, San Diego, CA) and sequenced (GenBank accession number EF100779). Because there are only 11 amino acids different between the human and cloned cynomolgus monkey TRPV1 region, we introduced point mutations in human TRPV1 using the QuickChange site-directed mutagenesis kit (Stratagene, La Jolla, CA) to obtain a vector expressing cynomolgus monkey TRPV1 (K141E, T172D, D185G, L190F, H233N, T275P, I434T, G470E, M503V, D605N, A620G). Because the residues that are mutated span amino acids 112-727, cynomolgus monkey TRPV1 cDNA contains $\mathrm{N}$ and C termini from human TRPV1. CHO cells stably expressing cynomolgus monkey TRPV1 were generated as described previously for rat TRPV1 (Gavva et al., 2004).

The partial dog TRPV1 cDNA sequence was assembled from dog genomic DNA. Amplification of the dog TRPV1 gene from exon 3 to exon 15 was performed using the Long Template PCR kit (Roche Diagnostics, Alameda, CA) in eight different reactions. The DNA sequence corresponding to each exon was then used to assemble the final predicted dog TRPV1 cDNA sequence that encodes amino acids 111-770 corresponding to human TRPV1. The critical residues for agonist and antagonist binding within TRPV1 are present in transmembrane regions 2-4 (Jordt and Julius, 2002; Chou et al., 2004; Gavva et al., 2004) and are conserved between rat, dog, monkey, and human TRPV1 (supplemental Fig. 3, available at www.jneurosci.org as supplemental material). Fulllength dog TRPV1 was made as a chimera containing N- and C-terminal human sequences corresponding to residues 1-111 and 771-839. A fulllength dog TRPV1 sequence was deposited to GenBank (accession number AY568758) after we assembled ours. The dog TRPV1 sequence that we used (amino acids 111-770) is identical to AY568758. HEK293 cells transiently transfected with pcDNA3.1 expression vector encoding dog TRPV1 cDNA [as described for rat TRPV1 (Gavva et al., 2004)] were used in agonist-induced ${ }^{45} \mathrm{Ca}^{2+}$ uptake assays. All of the agonistinduced ${ }^{45} \mathrm{Ca}^{2+}$ uptake assays that measure antagonism of TRPV1 were conducted essentially as described previously (Gavva et al., 2005b).

Capsaicin-induced flinch model. Male Sprague Dawley rats (Charles River Laboratories, Wilmington, MA) weighing 190-220 g were allowed at least $3 \mathrm{~d}$ of acclimation in the Amgen American Association for the Accreditation of Laboratory Animal Care-approved animal care facility before being used. Rats (eight per group) were pretreated with vehicle or single to various doses of TRPV1 antagonists in a dose volume of $5 \mathrm{ml} / \mathrm{kg}$ in Ora-Plus $/ 5 \%$ Tween 80 (oral gavage), $2 \mathrm{~h}$ before intraplantar injection of $0.5 \mathrm{mg}$ of capsaicin (Sigma-Aldrich, St. Louis, MO) in a volume of 25 $\mu \mathrm{l}$ of $5 \% \mathrm{EtOH}$ in PBS without $\mathrm{Ca}^{2+}$ and $\mathrm{Mg}^{2+}$. Immediately after the injection of capsaicin, the number of flinches was recorded over a $1 \mathrm{~min}$ period. Blood samples were collected immediately after behavioral testing for pharmacokinetic analysis.

Radiotelemetry in rats. Male Sprague Dawley rats (Charles River Laboratories) weighing 175-250 g (6-8 weeks of age) were single housed and allowed a 1 week acclimation in the animal care facility before the start of the experiment. The temperature in the room used for radiotelemetry experiments was maintained at $20 \pm 2^{\circ} \mathrm{C}$. To implant the radiotelemetry probe (model ER-4000 PDT; Mini Mitter, Brend, OR), rats were lightly anesthetized using isoflurane (IsoFlo; Abbott Laboratories, Chicago, IL) at a concentration of $2 \%$ isoflurane at $2 \mathrm{~L} / \mathrm{min}$ oxygen flow. In right lateral recumbence, the left lateral abdominal wall was clipped and cleaned with Betadine solution (Purdue Frederick Company, Stamford, CT) followed by $70 \%$ alcohol in water. A 3-4 $\mathrm{mm}$ incision was made through the skin and abdominal wall, into which a sterilized probe was inserted. The surgical site was closed with absorbable suture material (4-0 vicryl; Ethicon, Somerville, NJ) and black silk suture material (4-0; Ethicon), and the animals were returned to their home cage for recovery and allowed $3 \mathrm{~d}$ of recovery before the drug experiment.

On the day of the experiment, single-housed animals were placed on the radiotelemetry receivers. The baseline of body core temperature was recorded for $30 \mathrm{~min}$ before the drug administration. Rats (eight per group) were either treated with vehicle or single to various doses of TRPV1 antagonists in a dose volume of $5 \mathrm{ml} / \mathrm{kg}$ in Ora-Plus/5\% Tween 80 (oral gavage), and the body core temperature recordings were continued for 2 more hours. Blood samples were collected immediately after behavioral testing for pharmacokinetic analysis.

Body temperature measurements in dogs. Female Beagle dogs (Marshall Farms, North Rose, NY) weighing $\sim 7-12 \mathrm{~kg}$ that were surgically implanted with D70-PCT telemetry transmitters (Data Sciences International, St. Paul, MN) were used. During the monitoring phase (before and after the dose), all dogs were single housed in stainless steel cages. Two groups of animals (three per group) were treated with a single dose of the vehicle (2\% Pluronic F108 in Ora-Plus) or $30 \mathrm{mg} / \mathrm{kg}$ $(N-\{4-[(\{[(4$-tert-butylbenzyl)amino $]$ carbonothioyl $\}$ amino $)$ methyl $]-2-$ fluorophenyl $\}$ methanesulfonamide (JYL1421) via oral gavage at a dose volume of $5 \mathrm{ml} / \mathrm{kg}$. All doses were administered using appropriately sized oral gavage feeding tubes and syringes, followed by a flush of $\sim 5-10 \mathrm{ml}$ of municipal tap water.

Animal health was monitored across the course of the study with clinical observations and body weights. Beginning $\sim 1.5 \mathrm{~h}$ before dose administration and continuing until $24 \mathrm{~h}$ after dose administration, body temperature, motor activity, arterial blood pressure (systolic, mean, and diastolic), and heart rate were recorded from each animal for $20 \mathrm{~s}$ at $3 \mathrm{~min}$ intervals (unless the animal was removed from the cage for blood collection or detailed observation). All of the data were recorded and integrated on a telemetry computer system (Data Acquisition software, version 2.2; Data Sciences International). For pharmacokinetics analysis of JYL1421, blood samples were collected $\sim 2,4,8$, and $24 \mathrm{~h}$ after dose administration and processed to plasma. Concentrations of JYL1421 in the plasma were determined by liquid chromatography/tandem mass spectrometry analysis. Individual plasma concentration time data were analyzed by noncompartmental methods using WinNonlin version $4.1 \mathrm{e}$ Build 200408051632 (Pharsight, Mountain View, CA). At the end of the study, all animals were returned to the colony.

Body temperature measurements in monkeys. Male cynomolgus monkeys (Macaca fascicularis) weighing $\sim 3-7.3 \mathrm{~kg}$ were surgically implanted with Data Sciences International telemetry transmitters (contract service provided by SNBL USA, Everett, WA). During the monitoring phase (before and after dose administration), all cynomolgus monkeys were single housed. The temperature in the room used for radiotelemetry experiments was maintained at $24 \pm 2^{\circ} \mathrm{C}$. Two groups of animals (three per group) were treated with a single dose of the vehicle (2\% Pluronic F108 in Ora-Plus) or $100 \mathrm{mg} / \mathrm{kg} \mathrm{JYL1421} \mathrm{via} \mathrm{a} \mathrm{nasogastric} \mathrm{tube} \mathrm{into} \mathrm{the}$ stomach at a dose volume of $10 \mathrm{ml}$ followed by an air flush of $\sim 5 \mathrm{ml}$. Data acquisition and analysis was done using the telemetry system that consisted of the Open A.R.T. (version 2.2)/PONEMAH physiology platform (version 3.322). For pharmacokinetics analysis of JYL1421, blood samples were collected $\sim 2,4,8$, and $24 \mathrm{~h}$ after the dose administration and processed to plasma.

Statistical analysis. All core body temperature data by radiotelemetry of single-dose compounds were compared by $t$ test analysis of the average temperature during the specified duration after the drug administration. For experiments with multiple doses including radiotelemetry and cap- 
saicin flinch, a one-way ANOVA with Dunnett's test of each dose versus vehicle was used.

Reagents. All of the cell culture reagents were purchased from Invitrogen (Carlsbad, CA). All TRPV1 antagonists used in this study were synthesized at Amgen. Methods for synthesis of TRPV1 antagonists used in this study were described in recent publications (Valenzano et al., 2003; Wang et al., 2003; Doherty et al., 2005; El Kouhen et al., 2005; Xi et al., 2005; Ognyanov et al., 2006).

\section{Results}

\section{TRPV1 antagonists representing multiple different} chemotypes cause hyperthermia

In our efforts to identify a TRPV1 antagonist for clinical evaluation, we synthesized a variety of novel small molecule antagonists (Doherty et al., 2005; Xi et al., 2005; Ognyanov et al., 2006) (data not shown). To measure antagonism of TRPV1 in vivo, we and others tested the ability of antagonists to block capsaicin-induced eye wipe (Gavva et al., 2005b; Jakab et al., 2005), capsaicininduced hypothermia (Bannon et al., 2004; Jakab et al., 2005; Swanson et al., 2005), and/or capsaicin-induced flinch behavior (Seabrook et al., 2002) in rats. We previously showed that AMG9810 is a potent antagonist of TRPV1 in vitro and blocks capsaicin-induced eye wipe in rats (Gavva et al., 2005b). Here, we evaluated whether AMG9810 can inhibit capsaicin-induced hypothermia in rats implanted with radiotelemetry probes to monitor body temperature (Fig. 1a). AMG9810 not only inhibited capsaicin-induced hypothermia but also caused an $\sim 1^{\circ} \mathrm{C}$ increase in body temperature (hyperthermia) by itself within 30 min after administration (Fig. 1) (Bannon et al., 2004). Ten to 30 min after vehicle administration, the average temperature in the vehicle/vehicle group was $37.56 \pm 0.11^{\circ} \mathrm{C}(n=5)$, which as expected was comparable to the vehicle/capsaicin group $(n=6)$, because only the vehicle had been administered in both groups during this time period (Fig. 1a). The average temperature in the AMG9810-treated group (AMG9810/capsaicin) was $38.37 \pm$ $0.13^{\circ} \mathrm{C}(n=6)$, which was significantly higher than the vehicle/ vehicle group temperature $\left(F_{(2,14)}=14.92 ; p<0.01\right)$. Forty to $100 \mathrm{~min}$ after additional vehicle or capsaicin administration, the average temperature of the vehicle/capsaicin group mean of $35.93 \pm 0.17^{\circ} \mathrm{C}(n=5)$ was significantly lower (hypothermia) than the vehicle/vehicle group mean of $37.20 \pm 0.16^{\circ} \mathrm{C}(n=5$; $t=4.75 ; p<0.001)$. AMG9810 inhibited capsaicin-induced hypothermia with a group mean temperature of $37.02 \pm 0.21^{\circ} \mathrm{C}$ (AMG9810/capsaicin; $n=6$ ), which was significantly higher than the vehicle/capsaicin group temperature $(t=4.27 ; p<0.01)$. Additionally, we assessed the effect of AMG9810 alone on core body temperature over time (Fig. $1 b$ ). The maximum average temperature of $38.93 \pm 0.16^{\circ} \mathrm{C}(n=6)$ observed $20 \mathrm{~min}$ after dosing was significantly higher than the vehicle group mean temperature of $38.01 \pm 0.15^{\circ} \mathrm{C}(n=5 ; t=4.20 ; p<0.01)$. The average temperature after AMG9810 administration was also significantly higher at $30 \mathrm{~min}\left(38.77 \pm 0.18^{\circ} \mathrm{C} ; n=6\right)$ relative to the vehicle-treated group $\left(37.86 \pm 0.14^{\circ} \mathrm{C} ; n=5 ; t=3.85 ; p<0.01\right)$.

To investigate whether all TRPV1 antagonists cause hyperthermia, we evaluated the effect of various structurally distinct TRPV1 antagonists on body temperature in rats. First, we identified several compounds representing different chemotypes that block TRPV1 activation by capsaicin, protons, and heat (compounds A through $\mathrm{H}$ ) (Table 1 ). To investigate the specific contributions of the antagonism of capsaicin, protons ( $\mathrm{pH} 5.5$ and 5 ), and heat activation of TRPV1 to hyperthermia, we subsequently examined antagonism data for several hundred compounds and found that (1) most compounds that blocked capsaicin activation also blocked heat activation and (2) a small group
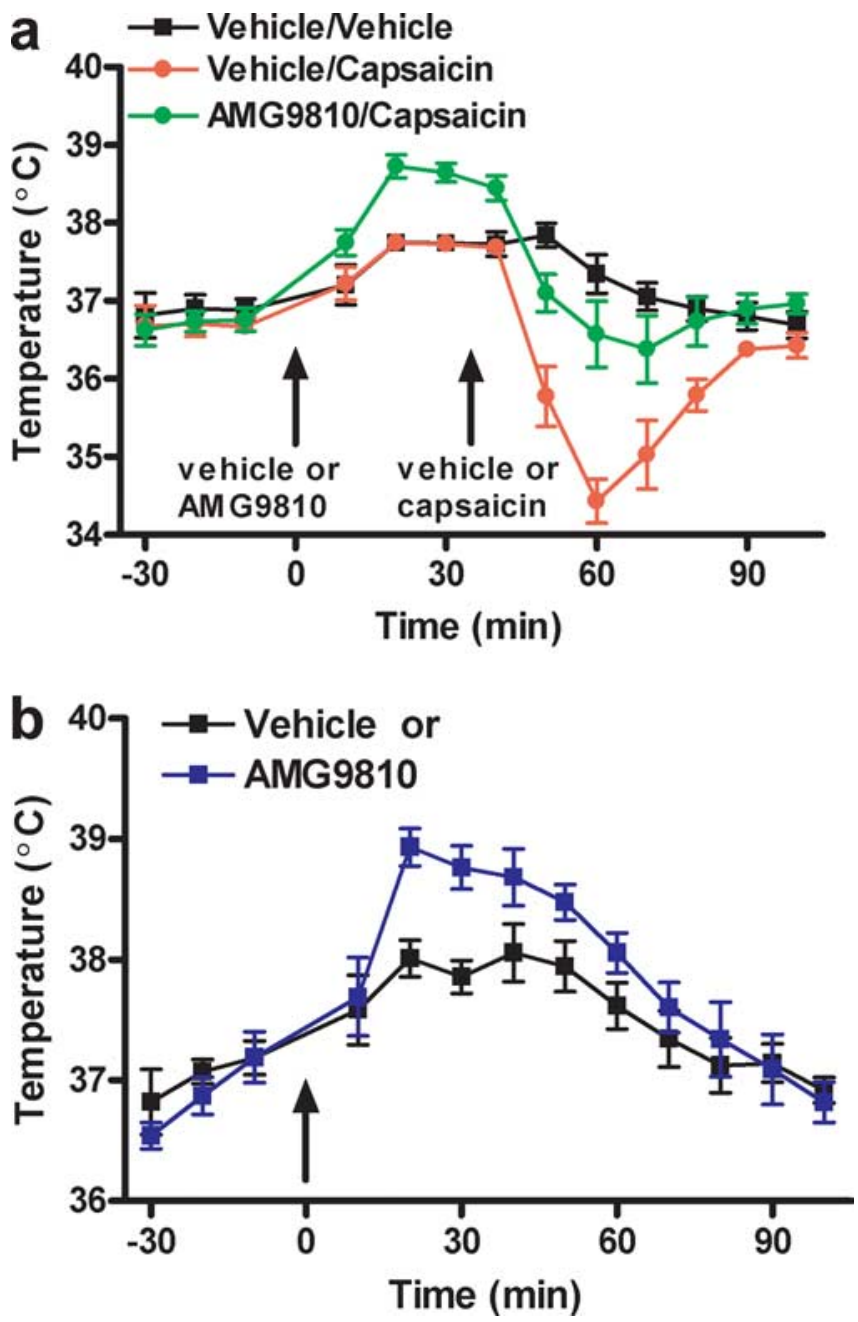

Figure 1. AMG9810 blocks capsaicin-induced hypothermia and causes hyperthermia by itself in rats. $\boldsymbol{a}$, Body temperatures of rats recorded from implanted radiotelemetry probes. Rats were first administered with either vehicle or $30 \mathrm{mg} / \mathrm{kg}$ AMG 9810 intraperitoneally and $30 \mathrm{~min}$ later were challenged with capsaicin $(20 \mu \mathrm{g} / 20 \mu \mathrm{l})$. Note that the capsaicin-induced decrease in body temperature of rats at 60 min was greater in the vehicle/capsaicin group (red) compared with the AMG9810/capsaicin group (green) $(t=4.63 ; p<0.001)$. AMG9810 caused a significant increase in rat body temperature at 20 and $30 \min \left(F_{(2,14)}=20.98 ; F_{(2,14)}=26.60 ; p<\right.$ 0.001). $\boldsymbol{b}$, Body temperature of rats administered with either vehicle or $30 \mathrm{mg} / \mathrm{kg}$ AMG9810 intraperitoneally. A significant increase in body temperature was seen 20 and 30 min after AMG9810 administration ( $t=4.20$ and 3.85; $p<0.01$ ). Error bars indicate SEM.

of compounds that block capsaicin and heat activation were ineffective against blocking proton activation (e.g., compounds I and J) (Table 1). Finally, we evaluated a large number of compounds (including compounds A through J; chemical structures are shown in supplemental Fig. 1, available at www.jneurosci.org as supplemental material) for their effect on body temperature in rats. Body temperature in rats increased by $0.5-1.5^{\circ} \mathrm{C}$ within 30-90 min after administration of all TRPV1 antagonists tested, but not after treatment with the vehicle (Table 1) (supplemental Fig. 2, available at www.jneurosci.org as supplemental material, and data not shown). These observations suggested that antagonist-induced hyperthermia is not chemotype specific but rather occurs because of TRPV1 antagonism. Furthermore, the data suggested that antagonism of capsaicin (and by inference proposed endogenous chemical ligands) and heat activation of TRPV1 is sufficient to cause hyperthermia. 
Table 1. In vitro profile of TRPV1 antagonists representing different chemotypes and their effect on body temperature in rats

\begin{tabular}{|c|c|c|c|c|c|c|c|c|c|c|c|c|}
\hline Compound & $\begin{array}{l}\text { Human } \\
\text { capsaicin }\end{array}$ & $\begin{array}{l}\text { Human } \\
\text { pH } 5\end{array}$ & $\begin{array}{l}\text { Rat } \\
\text { capsaicin }\end{array}$ & Rat pH 5 & Rat pH 5.5 & Rat heat & $\begin{array}{l}\mathrm{BCT} \\
\text { increase } \\
\left({ }^{\circ} \mathrm{C}\right)\end{array}$ & $\begin{array}{l}p \text { value } \\
\text { comparing } \mathrm{BCT} \\
\text { at } 60 \text { min } \\
\text { veh group }\end{array}$ & $\begin{array}{l}\text { Veh peak BCT } \\
\text { (mean } \pm \text { SEM) }\end{array}$ & $\begin{array}{l}\text { Compound peak BCT } \\
\text { (mean } \pm \text { SEM) }\end{array}$ & $\begin{array}{l}p \text { value comparing } \\
\text { peak values }\end{array}$ & $\begin{array}{l}\text { Dose } \mathrm{mg} / \mathrm{kg} \\
\text { (route) }\end{array}$ \\
\hline A & $23 \pm 3$ & $110 \pm 15$ & $79 \pm 9$ & $349 \pm 66$ & $24 \pm 2$ & $9 \pm 1$ & 0.6 & 0.0156 & $37.7 \pm 0.1$ & $38.6 \pm 0.2$ & 0.0038 & 30 (i.p.) \\
\hline B & $0.3 \pm 0.1$ & $0.7 \pm 0.2$ & $0.4 \pm 0.3$ & $0.5 \pm 0.6$ & $0.2 \pm 0.1$ & $0.1 \pm 0.02$ & 1.4 & 0.0015 & $37.8 \pm 0.2$ & $39.1 \pm 0.2$ & 0.0015 & 3 (i.v.) \\
\hline$C$ & $83 \pm 12$ & $26 \pm 2$ & $42 \pm 6$ & $10 \pm 1$ & $1 \pm 0.3$ & $24 \pm 8$ & 1.1 & 0.0038 & $37.7 \pm 0.1$ & $38.7 \pm 0.2$ & 0.002 & 30 (р.0.) \\
\hline D & $14 \pm 2$ & $20 \pm 3$ & $17 \pm 1$ & $13+1$ & $2 \pm 0.6$ & $3 \pm 1$ & 0.8 & 0.009 & $37.8 \pm 0.2$ & $38.7 \pm 0.2$ & 0.0068 & 3 (i.v.) \\
\hline$E$ & $2 \pm 0.1$ & $1 \pm 0.1$ & $1 \pm 0.2$ & $2 \pm 0.2$ & $0.5 \pm 0.1$ & $0.6 \pm 0.1$ & 1.1 & 0.004 & $37.7 \pm 0.1$ & $38.7 \pm 0.2$ & 0.0002 & 3 (р.0.) \\
\hline $\mathrm{F}$ & $1 \pm 0.1$ & $9 \pm 3$ & $10 \pm 2$ & $>4000$ & $13 \pm 2$ & $58 \pm 4$ & 1 & $<0.0001$ & $37.9 \pm 0.1$ & $39.0 \pm 0.1$ & $<0.0001$ & 30 (р.0.) \\
\hline G & $2 \pm 0.2$ & $1 \pm 0.2$ & $1 \pm 0.1$ & $1+0.1$ & $0.6 \pm 0.1$ & $2 \pm 0.1$ & $0.5^{*}$ & 0.0294 & $38.0 \pm 0.2$ & $38.2 \pm 0.1$ & $>0.05$ & 30 (р.о.) \\
\hline$H$ & $38 \pm 2$ & $88 \pm 19$ & $18 \pm 3$ & $70 \pm 5$ & $19 \pm 5$ & $16 \pm 9$ & $0.7^{*}$ & 0.0412 & $37.7 \pm 0.1$ & $38.3 \pm 0.3$ & $>0.05$ & 30 (р.0.) \\
\hline I & $0.2 \pm 0.1$ & $>4000$ & $1 \pm 0.5$ & $>4000$ & $>4000$ & $23 \pm 6$ & 0.4 & 0.005 & $38.1 \pm 0.1$ & $38.5 \pm 0.1$ & $>0.05$ & 3 (i.v.) \\
\hline J & $12 \pm 1$ & $>4000$ & $14 \pm 2$ & $>4000$ & $>4000$ & $360 \pm 97$ & 0.8 & 0.04 & $38.1 \pm 0.2$ & $38.8 \pm 0.1$ & 0.0143 & 3 (i.v.) \\
\hline
\end{tabular}

$\mathrm{IC}_{50}$ values against capsaicin, $\mathrm{pH} 5$ and 5.5 , and heat $\left(45^{\circ} \mathrm{C}\right)$ activation are in nanomolars. Body core temperature $(\mathrm{BCT})$ increases shown are recorded 60 min after dosing. Asterisk indicates body temperature increase 90 min after dosing. Veh Vehicle. Compound A, AMG9810; compound B, BCTC [N-(4-tertiarybutylphenyl)-4-(3-cholorphyridin-2-yl)tetrahydropyrazine-1 (2H)-carbox-amide; compound C, 7-tert-butyl-6-(4-chlorophenyl)-2-thioxo-2,3-dihydropyrido[2.3-d]pyrimidin-4(1H)-one; compound D, 4-(3-chloropyridin-2-yl)-N-[4-(trifluoromethyl)phenyl]benzamide; compound E, N-[4-(trifluoromethyl)phenyl]-7-[3[(trifluoromethyl)pyridin-2-yl]]quinazolin-4-amine; compound F, A-425619, N-isoquinolin-5-yl-N'-[4-(trifluoromethyl) benzyl] urea; compound G, 1-(5-chloro-6-\{(3R)-3-methyl-4-[6-(trifluoromethyl)-4-(3,4,5-trifluoropheynl)-1H-benzimidazol-2-yl]piperazin-1-yl\}pyridin-3-yl)ethane-1,2-diol; compound H,2-[(2,6-dichlorophenyl)amino]-N-[4-(trifluoromethyl)phenyl]1,3-thiazole-4-carboxamide; compound I, 8-(\{6-[4-(trifluoromethyl)phenyl]pyrimidin-4-yl\}oxy)isoquinolin-3-ol; compound J, 4-(\{6-[2-[(2-piperidin-1-ylethyl)amino]-6-(trifluoromethyl)pyridin-3-yl]]pyrimidin-4-yl\}oxy)-1, 3-benzothiazol-2-amine.

Table 2. Antagonism profile and pharmacokinetic properties of TRPV1 antagonists

\begin{tabular}{|c|c|c|c|c|c|c|c|c|c|c|c|}
\hline Compound & Capsaicin & $\mathrm{pH} 5$ & pH 5.5 & Heat & Rat p.o.\%F & Rat p.o. Cmax & Rat POAUC_0-t & $\begin{array}{l}\text { Capsaicin-induced flinch } \\
\text { (\% inhibition) }\end{array}$ & Plasma (ng/ml) & Brain $(n g / g)$ & $\begin{array}{l}\text { Brain-to- } \\
\text { plasma ratio }\end{array}$ \\
\hline AMG8163 & $0.6 \pm 0.3$ & $0.59 \pm 0.3$ & $0.35 \pm 0.25$ & $0.15 \pm 0.1$ & 6 & 62 & 318 & 100 at $3 \mathrm{mg} / \mathrm{kg}$ & 49.5 & 27.8 & 0.58 \\
\hline AMG3731 & $5.8 \pm 5.2$ & $6.6 \pm 1.0$ & $0.8 \pm 0.2$ & $4.8 \pm 0.4$ & 16 & 772 & 7182 & $\begin{array}{l}88 \text { at } 3 \text { mg/kg } 100 \text { at } 10 \\
\mathrm{mg} / \mathrm{kg}\end{array}$ & 7652658.6 & 23133 & 0.030 .05 \\
\hline AMG1629 & $0.57 \pm 0.4$ & $1.1 \pm 0.1$ & $0.08 \pm 0.02$ & $0.16 \pm 0.01$ & 10.4 & 80.5 & 644 & 100 at $1 \mathrm{mg} / \mathrm{kg}$ & 100.3 & 4.6 & 0.05 \\
\hline
\end{tabular}

$\mathrm{IC}_{50}$ values against capsaicin, $\mathrm{pH} 5$ and 5.5 , and heat $\left(45^{\circ} \mathrm{C}\right)$ activation of rat TRPV1 are shown in nanomolars. IC 50 values of these compounds against closely related TRP channels (TRPA1, TRPM8, TRPV3, and TRPV4) are $>4000 \mathrm{~nm}$. Note, AMG3731 is 10-fold less potent in blocking different modes of rat TRPV1 activation compared to others. \% F, Percentage of oral bioavailability at $5 \mathrm{mg} / \mathrm{kg}$; Cmax, maximum plasma concentration at $5 \mathrm{mg} / \mathrm{kg}$; AUC_0-t, concentration area under the curve from time 0 to the last time point measured at $5 \mathrm{mg} / \mathrm{kg}$.

\section{Both brain-penetrant and peripherally restricted TRPV1 antagonists cause hyperthermia}

To evaluate whether peripheral restriction of antagonists eliminates hyperthermia, we synthesized several compounds with decreased $\log \mathrm{P}$ (octanol/water partition coefficient), increased polar surface area, and an increased number of hydrogen-bond donors to restrict their CNS penetration. Here, we evaluated in vitro and in vivo pharmacology, brain penetration, and pharmacokinetic properties of three molecules in detail. Tert-butyl-2-(6$\{[2$-(acetylamino)-1,3-benzothiazol-4-yl] oxy\}pyrimidin-4-yl)5-(trifluoromethyl)phenylcarbamate (AMG8163), N-[4-(\{[3\{6-[(2-amino-1,3-benzothiazol-4-yl)oxy]pyrimidin-4-yl)\}-6(trifluoromethyl)pyridin-2-yl] amino\}methyl)-2-fluorophenyl]methanesulfonamide (AMG3731), and 3-amino-5-(\{2[(2-methoxyethyl)amino]-6-[4-(trifluoromethyl)phenyl] pyrimidin-4-yl\}oxy)quinoxalin-2(1H)-one (AMG1629) block capsaicin, proton, and heat activation of rat TRPV1 potently with $\mathrm{IC}_{50}$ values $<7 \mathrm{~nm}$ (Table 2 ). All three antagonists are $>4000$-fold selective relative to the closely related TRP channels (TRPV2, TRPV3, TRPV4, TRPA1, and TRPM8; data not shown). All three antagonists are orally bioavailable with pharmacokinetic properties that are amenable for in vivo studies (Table 2). Intraplantar injection of capsaicin induces paw flinching in rats, and TRPV1 antagonists block this behavior (Seabrook et al., 2002). We tested each one of the three antagonists delivered orally for their ability to block capsaicin-induced flinch in rats as a measure of TRPV1 antagonism in vivo. All three antagonists, AMG8163, AMG3731, and AMG1629, blocked $100 \%$ of capsaicin-induced flinch at doses of 3, 10, and $3 \mathrm{mg} / \mathrm{kg}$, respectively (Table 2). Plasma and brain concentrations of these antagonists measured in rats used in the capsaicin-induced flinch study and in another study after intravenous administration to rats indicated that AMG8163 was brain penetrant (brain/plasma ratio, 0.18-0.5), whereas AMG3731 and AMG1629 were relatively peripherally restricted molecules (brain/plasma ratios: $0.02,-0.05$, and $\sim 0.05$, respectively) (Table 2 and data not shown).

Next, we evaluated the effect of all three TRPV1 antagonists on body temperature (Table 2, Fig. $2 a-c$ ). AMG8163 caused hyperthermia of $1-1.5^{\circ} \mathrm{C}$ within $30-60 \mathrm{~min}$ after administration in rats (Fig. 2a). The maximum body temperature in the AMG8163administered group was $38.23 \pm 0.24^{\circ} \mathrm{C}(n=6)$, which occurred $50 \mathrm{~min}$ after dosing and was significantly higher than the maximum vehicle group temperature of $37.18 \pm 0.18^{\circ} \mathrm{C}(n=5 ; t=$ 3.43; $p<0.01)$. Similar to brain-penetrant AMG8163, both AMG3731 and AMG1629 caused hyperthermia of $0.5-1.2^{\circ} \mathrm{C}$ within 30-60 min after their administration (Fig. 2b,c). The maximum temperature in the AMG3731-administered group was $38.49 \pm 0.30^{\circ} \mathrm{C}(n=6)$, which occurred 50 min after dosing and was significantly higher than the maximum temperature of the vehicle group, which was $37.18 \pm 0.18^{\circ} \mathrm{C}(n=5 ; t=3.56$; $p<0.01)$. The maximum temperature in the AMG1629 -administered group was $38.09 \pm 0.11^{\circ} \mathrm{C}(n=5)$, which occurred $20 \mathrm{~min}$ after dosing and was significantly higher than the maximum temperature of the vehicle group, which was $37.45 \pm 0.10^{\circ} \mathrm{C}(n=5$; $t=4.19 ; p<0.01)$. Brain and plasma concentrations of AMG3731 and AMG1629, determined from the same rats, confirmed their peripheral restriction (brain/plasma ratios were 0.03 and 0.05 , respectively). In addition to AMG3731 and AMG1629, two other peripherally restricted antagonists, 3-amino-5-((2(((1S)-1-(2-pyridinyl)ethyl)amino)-6-(4-(trifluoromethyl)phenyl)-4-pyrimidinyl)oxy)-2(1H)-quinoxalinone (AMG1394) and 3-amino-5-((6-(2-((2-(methyloxy)ethyl)amino)-6-(trifluoro- 
methyl)-3-pyridinyl)-4-pyrimidinyl) oxy)-2(1H)-quinoxalinone (AMG2915) (both with a brain/pasma ratio of 0.04 ), also caused hyperthermia in rats (data not shown).

\section{TRPV1 antagonist-induced} hyperthermia is transient in nature To understand whether hyperthermia correlates with plasma concentrations of TRPV1 antagonists, we administered different oral doses of AMG8163 to rats implanted with radiotelemetry probes and monitored their temperatures for $24 \mathrm{~h}$ (Fig. 2d). AMG8163-induced hyperthermia showed a steep dose dependence, with $0.1 \mathrm{mg} / \mathrm{kg}$ causing a $0.5^{\circ} \mathrm{C}$ increase in body temperature and both 1 and $10 \mathrm{mg} / \mathrm{kg}$ causing a maximal increase of $1-1.5^{\circ} \mathrm{C}$ in body temperature that reached a plateau at $38.5^{\circ} \mathrm{C}$. ANOVA at each time point revealed the greatest $F$ value $\left(F_{(3,18)}=23.73\right.$; $p<0.01) 5 \mathrm{~h}$ after dosing: vehicle, $36.99 \pm$ $0.08^{\circ} \mathrm{C} ; 0.1 \mathrm{mg} / \mathrm{kg}, 37.31 \pm 0.08^{\circ} \mathrm{C}(p<$ $0.05) ; 1 \mathrm{mg} / \mathrm{kg}, 37.63 \pm 0.08^{\circ} \mathrm{C}(p<0.01)$; $10 \mathrm{mg} / \mathrm{kg}, 37.92 \pm 0.08^{\circ} \mathrm{C}(p<0.01)$. The concentration of AMG8163 in the plasma collected at the end of the experiment (24 $\mathrm{h}$ after dosing) was $1.6 \pm 0.5,15.8 \pm 10.5$, and $81.3 \pm 52 \mathrm{ng} / \mathrm{ml}$ for the $0.1,1$, and 10 $\mathrm{mg} / \mathrm{kg}$ doses, respectively. Plasma concentrations of AMG8163 measured in several other studies also indicate that as little as $33.8 \pm 6.8 \mathrm{ng} / \mathrm{ml}$ was sufficient to trigger hyperthermia in rats [minimal effective concentration (MEC) of $33.8 \pm 6.8 \mathrm{ng} / \mathrm{ml}$ ]. In general, hyperthermia did not persist or correlate with plasma half-life or concentration of TRPV1 antagonists, indicating the "transient nature" of the hyperthermic effect. For example, the plasma concentration of AMG8163 at $24 \mathrm{~h}$ in rats treated with $10 \mathrm{mg} / \mathrm{kg}$ was $81.3 \pm 52 \mathrm{ng} / \mathrm{ml}$, which is approximately threefold higher than the MEC to induce hyperthermia. However, there was no significant difference in body temperature between vehicle- and AMG8163-administered rats at $12 \mathrm{~h}\left(F_{(3,18)}=2.22 ; p>0.05\right)$ or at $16 \mathrm{~h}$ and beyond $\left(F_{(3,18)}=\right.$ $0.28-2.27 ; p>0.05)$. The transient nature of the TRPV1-induced hyperthermia suggests a physiological tolerance that develops from the involvement of thermoeffector mechanisms, which bring body temperature toward the normal range once TRPV1 antagonists induce hyperthermia.

\section{JYL1421 does not cause transient hyperthermia in rats and potentiates $\mathrm{pH} 5$ activation of rat TRPV1}

Because JYL1421 (also known as SC0030) was suggested to be a peripherally restricted TRPV1 antagonist in rats (Suh et al., 2003; Wang et al., 2003), we evaluated the effects of JYL1421 on capsaicin-induced flinch behavior and body temperature in rats under the same conditions used for the AMG compounds. First, we evaluated JYL1421 in the capsaicin-induced flinch model at doses up to a maximum of $30 \mathrm{mg} / \mathrm{kg}$ (Fig. $3 a$ ). JYL1421 showed $100 \%$ inhibition of capsaicin-induced flinch behavior in rats at 30 $\mathrm{mg} / \mathrm{kg}\left(F_{(5,42)}=4.4 ; p<0.01 ; n=8\right)$, indicating complete ontarget coverage at the $30 \mathrm{mg} / \mathrm{kg}$ dose. Next, we evaluated the effects of JYL1421 (up to a maximum dose of $100 \mathrm{mg} / \mathrm{kg}$ ) on body temperature in rats and found that it did not cause hyperthermia
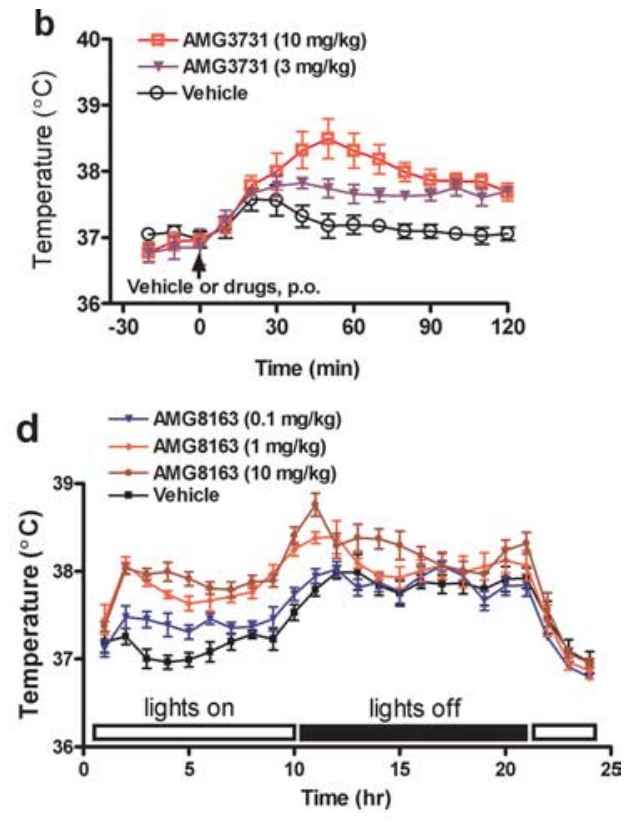

Time (min)

Figure 2. Both brain-penetrant (AMG8163) and peripherally restricted (AMG1629 and AMG3731) TRPV1 antagonists cause

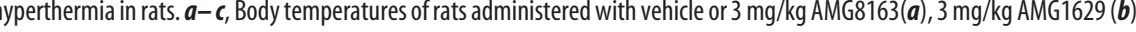
administration. Compared with vehicle treatment, all four antagonists caused significant increase in body temperature ( $p<$ Dunnett's multiple comparison to vehicle was significant at each time point for 1 and $10 \mathrm{mg} / \mathrm{kg}$ doses $(p<0.01)$. During hours $16-21$, ANOVA at each time point was nonsignificant $(p>0.05)$. Error bars indicate SEM

at any of the tested doses (Fig. 3b). An ANOVA test 10 min after dosing showed a significant difference $\left(F_{(4,30)}=2.91\right)$, although all subsequent Dunnett's multiple comparisons to the vehicletreated group were nonsignificant $(p>0.05)$. The highest temperature seen at any dose or time point was $37.51 \pm 0.09^{\circ} \mathrm{C}(n=$ 7) in the $30 \mathrm{mg} / \mathrm{kg}$ dose group $30 \mathrm{~min}$ after dosing, which was neither significantly different from the highest temperature seen in the vehicle group of $37.35 \pm 0.13^{\circ} \mathrm{C}(n=7) 20 \mathrm{~min}$ after dosing $(t=1.04 ; p>0.05)$ nor significantly different from the vehicle group temperature at the same $30 \mathrm{~min}$ time point $(37.32 \pm$ $\left.0.10^{\circ} \mathrm{C} ; n=7 ; t=1.44 ; p>0.05\right)$. Brain and plasma concentrations determined in rats indicated that JYL1421 was peripherally restricted with a brain/plasma ratio ranging between 0.05 and 0.07 . The plasma concentrations achieved at the 10 and $30 \mathrm{mg} / \mathrm{kg}$ doses, in both the capsaicin-induced flinch and telemetry experiments, were comparable.

Among the three peripherally restricted TRPV1 antagonists studied here, AMG3731 and AMG1629 caused hyperthermia in rats, whereas JYL1421 did not. Hence, we evaluated the pharmacology of JYL1421 in agonist-induced ${ }^{45} \mathrm{Ca}^{2+}$ uptake assays under the same assay conditions used for testing of AMG3731 and AMG1629 (Fig. 3c,d). JYL1421 acted as a full antagonist of capsaicin activation $\left(\mathrm{IC}_{50}=8 \mathrm{nM}\right)$ and as a partial antagonist of heat activation (maximal inhibition of $60 \%$ at $4 \mu \mathrm{M}$ ) of rat TRPV1 (Fig. 3c). In agreement with previous findings (Wang et al., 2003), JYL1421 partially blocked pH 5.5 activation in CHO cells expressing rat TRPV1 (Fig. $3 d$ ). Surprisingly, JYL1421 potentiated pH 5 activation in a concentration-dependent manner, as measured by the $\mathrm{pH} 5$-induced ${ }^{45} \mathrm{Ca}^{2+}$ uptake into $\mathrm{CHO}$ cells expressing rat TRPV1 (Fig. 3d). Under the same assay conditions, AMG3731 and AMG1629 completely and potently blocked both $\mathrm{pH} 5$ and pH 5.5 activation of rat TRPV1 (Table 2). We confirmed JYL1421 

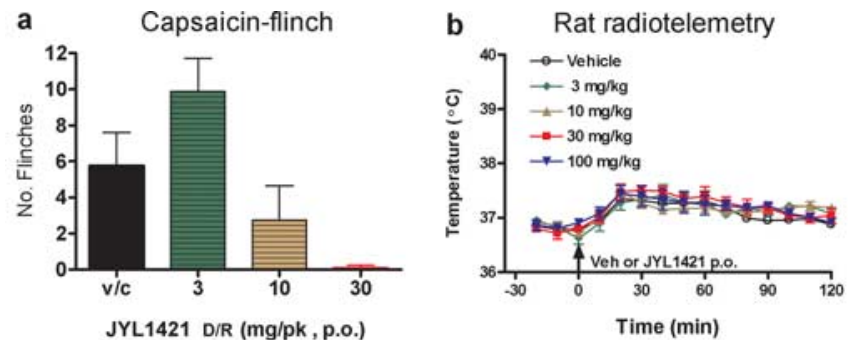

JYL1421 D/R (mg/pk, p.o.)
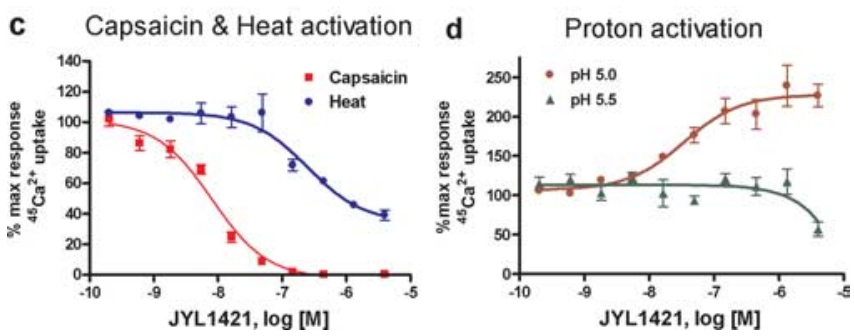

Figure 3. JYL1421 blocks capsaicin-induced flinch behavior in rats but does not induce body temperature changes. $\boldsymbol{a}$, JYL1421 blocks capsaicin-induced flinch in rats. Different doses (3-30 $\mathrm{mg} / \mathrm{kg}$ ) of JYL1421 were administered orally to rats $60 \mathrm{~min}$ before capsaicin challenge. The number (No.) of flinches in the first minute was counted and plotted against the dose of JYL1421. A 100\% inhibition of capsaicin-induced flinch was observed at $30 \mathrm{mg} / \mathrm{kg} \mathrm{JYL1421}$ $\left(F_{(3,27)}=10.68 ; n=8 ; p<0.05\right.$ only for $\left.30 \mathrm{mg} / \mathrm{kg}\right)$. Plasma concentrations of JYL1421 at 10 and $30 \mathrm{mg} / \mathrm{kg}$ were $2546 \pm 600$ and $14182 \pm 3953 \mathrm{ng} / \mathrm{ml}$, respectively. $\mathrm{v} / \mathrm{c}$, vehicle/capsaicin; $D / R$, dose response. $\boldsymbol{b}$, Body temperature of vehicle (veh) or different doses (range, 3-100 $\mathrm{mg} / \mathrm{kg}$ ) of JYL1421-administered (orally) rats. No significant change in body temperature was observed at all doses tested ( $p>0.05$ for all Dunnett's multiple comparisons at each time point). Plasma concentrations of JYL1421 at 10,30, and $100 \mathrm{mg} / \mathrm{kg}$ were $2725 \pm 3329,3876 \pm$ $1448,7867 \pm 3570 \mathrm{ng} / \mathrm{ml}$, respectively. c, Capsaicin $(0.5 \mu \mathrm{m})$-induced or heat $\left(45^{\circ} \mathrm{C}\right)$-induced ${ }^{45} \mathrm{Ca}^{2+}$ uptake into $\mathrm{CH} 0$ cells stably expressing rat TRPV1 in the absence $(100 \%)$ or presence of different concentrations of JYL1421. Note that JYL1421 fully blocks capsaicin (red) and partially blocks heat (blue) activation. $\boldsymbol{d}$, Low pH (proton)-induced ${ }^{45} \mathrm{Ca}^{2+}$ uptake into $\mathrm{CHO}$ cells expressing rat TRPV1 in the absence (100\%) or presence of different concentrations of JYL1421. JYL1421 shows partial inhibition of $\mathrm{pH} 5.5$-induced ${ }^{45} \mathrm{Ca}^{2+}$ uptake at the highest concentration tested $(4 \mu \mathrm{m})$. Note the potentiation of $\mathrm{pH} 5$-induced ${ }^{45} \mathrm{Ca}^{2+}$ uptake above $100 \%$ by JYL1421 at concentrations $>30$ nm. max, Maximum. Error bars indicate SEM.

potentiation of pH 5 activation multiple times $(n=8)$, and the maximal potentiation ranged from 124 to $254 \%$ (average, $203 \pm$ $41 \%$ ) relative to $\mathrm{pH} 5$ activation alone (Fig. $3 d$ and data not shown). JYL1421 by itself did not induce ${ }^{45} \mathrm{Ca}^{2+}$ uptake into $\mathrm{CHO}$ cells expressing the rat TRPV1 receptor at physiological $\mathrm{pH}$ ( $\mathrm{pH} 7.2$ ), indicating that it is not a partial agonist.

\section{JYL1421 blocks dog and cynomolgus monkey TRPV1} activation and causes hyperthermia in both species Because two peripherally restricted TRPV1 antagonists (AMG3731 and AMG1629) caused hyperthermia in rats, we hypothesized that potentiation of $\mathrm{pH} 5$ activation of rat TRPV1 by JYL1421 was responsible for the lack of hyperthermia in rats. We predicted that if JYL1421 blocks capsaicin and heat activation but does not potentiate $\mathrm{pH} 5$ activation of TRPV 1 from any species, it would cause hyperthermia in that species. To test this hypothesis, we evaluated the effect of JYL1421 on dog and cynomolgus monkey TRPV1 activation and body temperature in both species. First, we cloned and characterized TRPV1 cDNA from a dog [genomic sequencing followed by reverse transcriptase (RT)PCR] and monkey (RT-PCR followed by mutagenesis of 11 residues in human TRPV1 to those that are present in cynomolgus monkey). HEK293 cells transiently transfected with dog TRPV1 and $\mathrm{CHO}$ cells stably expressing monkey TRPV1 were activated by capsaicin with $\mathrm{EC}_{50}$ values comparable to rat and human
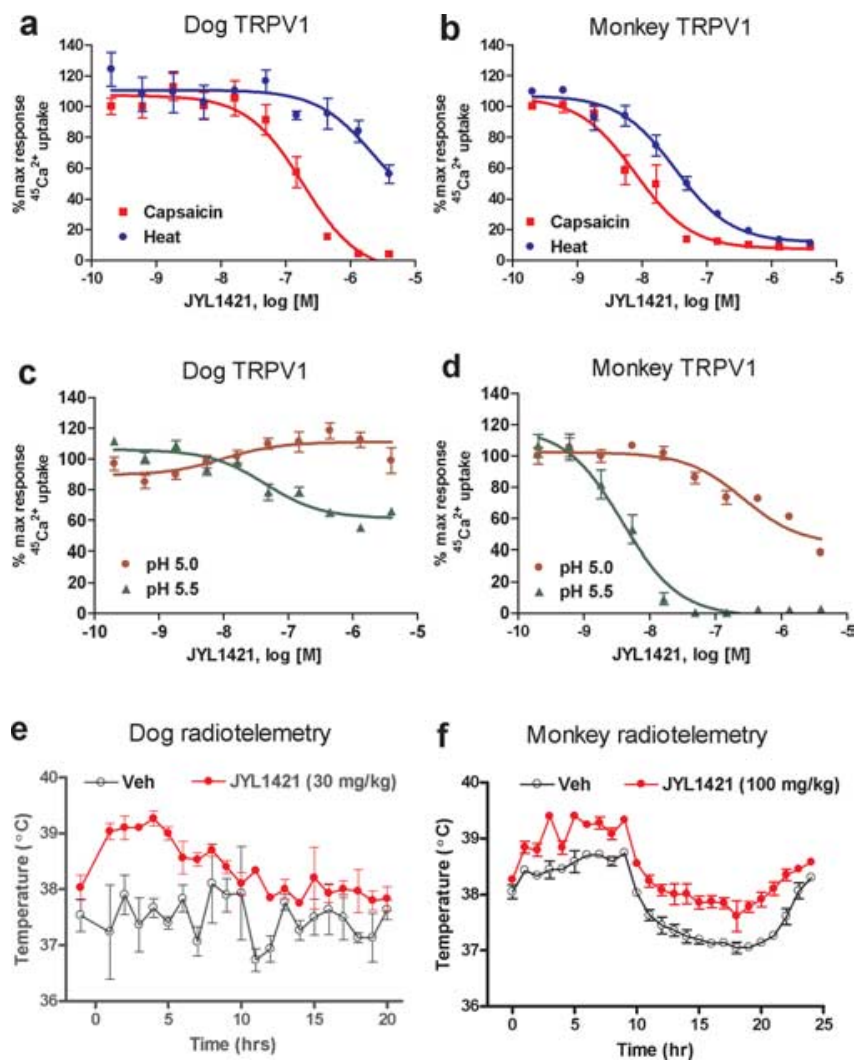

Figure 4. JYL1421 blocks capsaicin, heat, and proton activation of dog and cynomolgus monkey TRPV 1 and causes hyperthermia in both species. $\boldsymbol{a}$, Capsaicin $(0.5 \mu \mathrm{M})$-induced or heat $\left(45^{\circ} \mathrm{C}\right)$-induced ${ }^{45} \mathrm{Ca}^{2+}$ uptake into HEK293 cells transiently expressing dog TRPV1 in the absence $(100 \%)$ or presence of different concentrations of JYL1421. Note that JYL1421 fully blocks capsaicin (red) and partially blocks heat (blue) activation. $\boldsymbol{b}$, Capsaicin $(0.5 \mu \mathrm{m}$ )-induced or heat $\left(45^{\circ} \mathrm{C}\right)$-induced ${ }^{45} \mathrm{Ca}^{2+}$ uptake into $\mathrm{CHO}$ cells stably expressing cynomolgus monkey TRPV1 in the absence (100\%) or presence of different concentrations of JYL1421. Note that JYL1421 fully blocks capsaicin (red) and heat (blue) activation. c, Low pH (proton)-induced ${ }^{45} \mathrm{Ca}^{2+}$ uptake into HEK293 cells transiently expressing dog TRPV1 in the absence (100\%) or presence of different concentrations of JYL1421. JYL1421 shows partial inhibition of pH 5.5 -induced ${ }^{45} \mathrm{Ca}^{2+}$ uptake. $\boldsymbol{d}$, Low pH (proton)-induced ${ }^{45} \mathrm{Ca}^{2+}$ uptake into $\mathrm{CHO}$ cells expressing cynomolgus monkey TRPV1 in the absence (100\%) or presence of different concentrations of JYL1421. JYL1421 shows full block of pH 5.5 activation (green) and partially blocks pH 5 activation (brown). $\boldsymbol{e}$, Time course of body temperature of dogs administered with either vehicle or 30 $\mathrm{mg} / \mathrm{kg}$ JYL1421. JYL1421 caused a significant increase in body temperature compared with vehicle treatment from 1 to $5 \mathrm{~h}$ after administration $(t=3.01-8.94 ; p<0.05)$. $f$, Time course of body temperature of cynomolgus monkeys administered with either vehicle or $100 \mathrm{mg} / \mathrm{kg}$ JYL1421. JYL1421 caused a significant increase in body temperature compared vehicle treatment from 1 to $17 \mathrm{~h}$ after administration $(t=2.98-8.66 ; p<0.05)$. max, Maximum; Veh, vehicle. Error bars indicate SEM.

TRPV1 $\left(\mathrm{EC}_{50}\right.$ values were $112 \pm 10,94 \pm 11,69 \pm 8$, and $47 \pm 7$ nM for rat, dog, monkey, and human TRPV1, respectively). Similarly, protons and heat also activated both dog and monkey TRPV1 (Fig. 4 and data not shown). Next, we evaluated the ability of JYL1421 to block dog and monkey TRPV1 activation in agonist-induced ${ }^{45} \mathrm{Ca}^{2+}$ uptake assays. JYL1421 acted as a full antagonist of capsaicin activation (Fig. $4 a, b$ ) and as a partial to full antagonist of heat (Fig. $4 a, b$ ) and proton (Fig. $4 c, d$ ) activation of both dog and monkey TRPV1. Importantly, JYL1421 did not potentiate $\mathrm{pH} 5$ activation of either dog or monkey TRPV1 (Fig. $4 c, d)$.

Because JYL1421 blocks capsaicin, heat, and proton activation of dog and monkey TRPV1, which is similar to the antagonism profile of other peripherally restricted TRPV1 antagonists studied here (AMG3731 and AMG1629), we predicted that it would 
cause hyperthermia in dogs and monkeys. To test that, JYL1421 was administered orally to both dogs $(30 \mathrm{mg} / \mathrm{kg})$ and monkeys $(100 \mathrm{mg} / \mathrm{kg})$ implanted with radiotelemetry probes, and their body temperatures were recorded for $24 \mathrm{~h}$ (Fig. 4e,f).

In dogs, resting body temperatures of the JYL1421- and vehicle-treated groups at -1 and $0 \mathrm{~h}$ were not significantly different (JYL1421, 38.01 $\pm 0.22^{\circ} \mathrm{C}$ and $38.65 \pm 0.14^{\circ} \mathrm{C}, n=3$; vehicle, $37.41 \pm 0.38^{\circ} \mathrm{C}$ and $37.81 \pm 0.27^{\circ} \mathrm{C}, n=3 ; t=1.38$ and $t=2.77 ; p>0.05)$. Beginning at the first time point $(1 \mathrm{~h})$ after dosing, body temperature in the JYL1421-administered group rose to $38.94 \pm 0.22^{\circ} \mathrm{C}(n=3)$, which was significantly greater than that in the vehicle group $\left(37.03 \pm 0.62^{\circ} \mathrm{C} ; n=3 ; t=3.01\right.$; $p<0.05)$. The two groups remained significantly different from each other $(t=3.01-8.94 ; p<0.05-0.001)$ until 6 h after administration, when the temperature of the JYL1421 group dropped to $38.54 \pm 0.32^{\circ} \mathrm{C}(n=3$ and the temperature of the vehicle group was $37.72 \pm 0.33^{\circ} \mathrm{C}(n=3 ; t=1.79 ; p>0.05)$. At 7 and $8 \mathrm{~h}$, the two groups were significantly different (all respectively, $t=7.23$ and $3.25 ; n=3 ; p<0.05)$. At 9 and $10 \mathrm{~h}$, the groups were not significantly different $(t=1.56$ and $1.18 ; n=3 ; p>0.05)$. At 11 and $12 \mathrm{~h}$, the groups were again significantly different $(t=11.21$, $n=3, p<0.001$; and $t=5.50, n=2, p<0.05$ ). From 13 to $20 \mathrm{~h}$ ( $t$ test could not be done at hour 14 because of both dogs in the JYL1421 group having temperatures of $37.70^{\circ} \mathrm{C}$ ), the two groups were not significantly different $(t=0.37-1.72 ; n=2-3 ; p>$ $0.05)$. Mean serum concentrations $(n=3)$ in the JYL1421treated group were 5860, 4620, 1680 , and $97.8 \mathrm{ng} / \mathrm{ml}$ at 2, 4, 8, and $24 \mathrm{~h}$ after administration, respectively.

In monkeys, resting body temperatures of the JYL1421 and vehicle groups were not significantly different (JYL1421: $38.26 \pm$ $0.06^{\circ} \mathrm{C}, n=3$; vehicle: $38.05 \pm 0.12^{\circ} \mathrm{C}, n=3 ; t=0.18 ; p>0.05$ ). During hours 1-17, the JYL1421-treated group had a significantly higher body temperature than the vehicle group $(t=2.98-$ 8.66; $n=3 ; p<0.05-0.01)$, with a maximum temperature of $39.40 \pm 0.05^{\circ} \mathrm{C}(n=3)$ at $3 \mathrm{~h}$ and $39.40 \pm 0.03^{\circ} \mathrm{C}(n=3)$ at $5 \mathrm{~h}$, whereas the maximum mean temperature $(n=3)$ in the vehicletreated group was $38.74 \pm 0.08^{\circ} \mathrm{C}$ (at $9 \mathrm{~h}$ ). During hours $18-24$, mean body temperature in the JYL1421-treated group was significantly greater than in the vehicle-treated group $(t=3.95-6.78$; $n=3 ; p<0.05-0.01)$, except at $18 \mathrm{~h}(t=1.93 ; n=3 ; p<0.05)$ and $22 \mathrm{~h}(t=2.65 ; n=3 ; p>0.05)$. Mean serum concentrations $(n=3)$ in the JYL1421-treated group were 3761, 4236, 2570, and $712 \mathrm{ng} / \mathrm{ml}$ at $2,4,8$, and $24 \mathrm{~h}$ after administration, respectively.

Notably, no JYL1421-related clinical observations or alterations in food consumption, body weight, motor activity, or cardiovascular parameters were observed in dogs or monkeys. In summary, JYL1421 caused transient hyperthermia in both dogs (increase of $\sim 1.8^{\circ} \mathrm{C}$ ) and monkeys (increase of $0.5-1^{\circ} \mathrm{C}$ ), confirming that blocking TRPV1 activation (and not potentiating pH 5 activation) results in hyperthermia.

\section{Discussion}

By characterizing the in vitro and in vivo pharmacology of TRPV1 antagonists representing multiple chemotypes, we discovered that antagonists of all modes of TRPV1 activation as well as those that only block capsaicin and heat activation cause hyperthermia, demonstrating that blocking two modes of TRPV1 activation is sufficient to induce hyperthermia. Furthermore, we found that peripherally restricted TRPV1 antagonists cause hyperthermia in rats (AMG3731 and AMG1629), dogs (JYL1421), and monkeys (JYL1421), suggesting that peripheral restriction of antagonists by chemical modification does not eliminate hyperthermia caused by TRPV1 antagonism and that TRPV1 antagonists cause hyperthermia in multiple species, from rodents to primates. Hyperthermia is caused by the same dose of TRPV1 antagonists (both brain penetrant and peripherally restricted) that blocks capsaicin-induced flinch (on target coverage), indicating that coverage of the target (efficacy) in the flinch model and antagonist-induced hyperthermia are not separable. Therefore, TRPV1 antagonist-induced hyperthermia may represent a potential hurdle for development of TRPV1 antagonists as therapeutics for chronic pain conditions.

Although JYL1421 blocks capsaicin and heat activation of rat TRPV1, it did not cause hyperthermia in rats. However, JYL1421 has different pharmacology at the rat TRPV1 channels; specifically, it potentiates $\mathrm{pH} 5$ activation. The fact that JYL1421 causes hyperthermia in dogs and monkeys and blocks capsaicin, proton, and heat activation, but importantly does not potentiate dog and monkey TRPV 1 activation by $\mathrm{pH} 5$, also confirms that blocking TRPV1 activation in vivo results in hyperthermia. We do not know whether JYL1421 is peripherally restricted in dogs and monkeys; however, in light of the results with AMG1394, AMG1629, AMG2915, and AMG3731, we propose that blocking TRPV1 activation results in hyperthermia, even if the antagonists are predominantly restricted to the periphery.

Capsaicin, an agonist of TRPV1, when administered orally, subcutaneously, or intracerebrally produces hypothermia in a wide variety of animals and in humans (Hori, 1984). Two predominant mechanisms underlie the capsaicin-induced hypothermia; one mechanism induces substance $\mathrm{P}$ and calcitonin gene-related peptide (CGRP) release (Jhamandas et al., 1984; Holzer, 1991; Gavva et al., 2005b), which results in vasodilation in the periphery and therefore increases heat loss, and the second mechanism reduces metabolism (as measured by reduction in the oxygen consumption), which lowers heat production (Hori, 1984). Chronic effects of capsaicin on thermoregulation include irreversible desensitization and neuronal ablation that results in loss of hypothermia to subsequent capsaicin treatments (JancsoGabor et al., 1970a,b), indicating that capsaicin-induced hypothermia is mediated by its receptor, TRPV1. In line with this hypothesis, capsaicin did not cause hypothermia in TRPV1 knock-out mice (Caterina et al., 2000). Because agonists such as capsaicin and RTX cause hypothermia, it is reasonable to hypothesize that antagonists of TRPV1 might cause hyperthermia, but only if TRPV1 is tonically activated in vivo.

Antagonists representing multiple different chemotypes that block TRPV 1 activation by capsaicin, heat, and protons, as well as those that block only capsaicin and heat activation, causing transient hyperthermia, demonstrate the presence of tonic TRPV1 activation in vivo. Because the antagonists used in this study are selective for TRPV1, we believe that no other TRP channels contribute to antagonist-induced hyperthermia. Because both peripherally restricted and brain-penetrant antagonists caused hyperthermia, we propose that the regions with tonic TRPV1 activation are readily accessible to peripheral blood flow. The mechanism(s) of tonic TRPV1 activation may include the following: (1) activation by endogenous ligands (Van Der Stelt and Di Marzo, 2004); (2) phosphorylation and sensitization of TRPV1 by protein kinases, which result in the activation of TRPV1 at body temperature (Premkumar and Ahern, 2000); and/or (3) cleavage of phosphatidylinositol bisphosphate by phospholipase $\mathrm{C}$, releasing the TRPV1 from constitutive suppression (Chuang et al., 2001). Sensitization of TRPV1 by phosphorylation and phospholipase C activation-mediated release of TRPV1 from constitutive suppression may result from a small pool of activated 
G-protein-coupled receptors that are involved in constitutive processes and/or metabolic pathways that occur normally in cells.

The following facts demonstrate involvement of tonic TRPV1 activation in body temperature regulation: (1) agonists of TRPV1 cause hypothermia in rodents and humans (Hori, 1984); (2) there is an absence of agonist-induced hypothermia in TRPV1 knock-out mice (Caterina et al., 2000); (3) antagonists of TRPV1 representing multiple different chemotypes caused hyperthermia in rats (present study; Bannon et al., 2004; Swanson et al., 2005); (4) there is a correlation of antagonism of TRPV1 activation by JYL1421 with hyperthermia in dogs and monkeys (present study); (5) TRPV1 knock-out mice showed some impairment in thermoregulation (Szelenyi et al., 2004; Iida et al., 2005); and (6) there is an absence of antagonist-induced hyperthermia in TRPV1 knock-out mice (A. A. Steiner, V. F. Turek, J. J. S. Treanor, N. R. Gavva, and A. A. Romanovsky, unpublished data). Based on the heat or cold activation, a group of TRP channels expressed in sensory nerve endings and in the skin were proposed as "thermoTRP" channels (Patapoutian et al., 2003) to mediate thermosensation (Lee et al., 2005; Moqrich et al., 2005). Here, we extend the scope of this hypothesis to include thermoregulation and demonstrate that one of the thermoTRP channels, TRPV1, plays a critical role in body temperature regulation. TRPV1 antagonists causing hyperthermia in rats, dogs, and monkeys indicate the conserved function of TRPV1 in body temperature regulation from rodents to primates.

It has been established that warm-sensitive neurons in the preoptic/anterior hypothalamus $(\mathrm{PO} / \mathrm{AH})$ serve as first efferent neurons for several autonomic thermoeffectors and thus play a principal role in central control of thermoregulation (for review, see Boulant, 1981; Hori, 1984; Romanovsky, 2007). The presence of capsaicin-sensitive structures in the preoptic and in other areas of the hypothalamus was predicted in the early 1970s (Szolcsanyi et al., 1971) and confirmed later by other groups (Rabe et al., 1980; Hori et al., 1988; Acs et al., 1996; Szallasi and Blumberg, 1999; Toth et al., 2005). Because some parts of the PO/AH (e.g., the organum vasculosum of the lamina terminalis) are, in fact, outside of the blood-brain barrier (BBB) and peripherally restricted antagonists cause hyperthermia, we propose that the site of action for TRPV1 antagonist-induced hyperthermia is predominantly outside of the BBB. However, small amounts of peripherally restricted TRPV1 antagonists did penetrate the brain; hence, we cannot completely rule out CNS regions that are protected by the BBB contributing to hyperthermia. Although capsaicin causes vasodilation through substance $P$ and CGRP release from sensory neurons (Holzer, 1991), it is not known whether tonic TRPV1 activation is involved in maintenance of vasomotor tone. If it is indeed involved, then TRPV1 antagonists might cause vasoconstriction as one of the (peripheral) mechanisms of antagonist-induced hyperthermia. Additional studies will focus on elucidating the mechanisms of TRPV1 antagonist-induced hyperthermia.

\section{References}

Acs G, Palkovits M, Blumberg PM (1996) Specific binding of [3H]resiniferatoxin by human and rat preoptic area, locus ceruleus, medial hypothalamus, reticular formation and ventral thalamus membrane preparations. Life Sci 59:1899-1908.

Bannon AW, Davis JR, Zhu D, Norman MH, Doherty E, Magal E, Treanor J 2004 Involvement of trpvl in the regulation of body temperature in rats and mice. Soc Neurosci Abstr 30:890.24.

Boulant JA (1981) Hypothalamic mechanisms in thermoregulation. Fed Proc 40:2843-2850.

Caterina MJ, Schumacher MA, Tominaga M, Rosen TA, Levine JD, Julius D
(1997) The capsaicin receptor: a heat-activated ion channel in the pain pathway. Nature 389:816-824

Caterina MJ, Leffler A, Malmberg AB, Martin WJ, Trafton J, Petersen-Zeitz KR, Koltzenburg M, Basbaum AI, Julius D (2000) Impaired nociception and pain sensation in mice lacking the capsaicin receptor. Science 288:306-313.

Chou MZ, Mtui T, Gao YD, Kohler M, Middleton RE (2004) Resiniferatoxin binds to the capsaicin receptor (TRPV1) near the extracellular side of the S4 transmembrane domain. Biochemistry 43:2501-2511.

Chuang HH, Prescott ED, Kong H, Shields S, Jordt SE, Basbaum AI, Chao MV, Julius D (2001) Bradykinin and nerve growth factor release the capsaicin receptor from PtdIns(4,5)P2-mediated inhibition. Nature 411:957-962.

Clapham DE (2003) TRP channels as cellular sensors. Nature 426:517-524. Davis JB, Gray J, Gunthorpe MJ, Hatcher JP, Davey PT, Overend P, Harries MH, Latcham J, Clapham C, Atkinson K, Hughes SA, Rance K, Grau E, Harper AJ, Pugh PL, Rogers DC, Bingham S, Randall A, Sheardown SA (2000) Vanilloid receptor-1 is essential for inflammatory thermal hyperalgesia. Nature 405:183-187.

Dhaka A, Viswanath V, Patapoutian A (2006) Trp ion channels and temperature sensation. Annu Rev Neurosci 29:135-161.

Doherty EM, Fotsch C, Bo Y, Chakrabarti PP, Chen N, Gavva N, Han N, Kelly MG, Kincaid J, Klionsky L, Liu Q, Ognyanov VI, Tamir R, Wang X, Zhu J, Norman MH, Treanor JJ (2005) Discovery of potent, orally available vanilloid receptor-1 antagonists. Structure-activity relationship of $N$-aryl cinnamides. J Med Chem 48:71-90.

El Kouhen R, Surowy CS, Bianchi BR, Neelands TR, McDonald HA, Niforatos W, Gomtsyan A, Lee CH, Honore P, Sullivan JP, Jarvis MF, Faltynek CR (2005) A-425619 [1-isoquinolin-5-yl-3-(4-trifluoromethylbenzyl)-urea], a novel and selective transient receptor potential type V1 receptor antagonist, blocks channel activation by vanilloids, heat, and acid. J Pharmacol Exp Ther 314:400-409.

Gavva NR, Klionsky L, Qu Y, Shi L, Tamir R, Edenson S, Zhang TJ, Viswanadhan VN, Toth A, Pearce LV, Vanderah TW, Porreca F, Blumberg PM, Lile J, Sun Y, Wild K, Louis JC, Treanor JJ (2004) Molecular determinants of vanilloid sensitivity in TRPV1. J Biol Chem 279:20283-20295.

Gavva NR, Tamir R, Klionsky L, Norman MH, Louis JC, Wild KD, Treanor JJ (2005a) Proton activation does not alter antagonist interaction with the capsaicin-binding pocket of TRPV1. Mol Pharmacol 68:1524-1533.

Gavva NR, Tamir R, Qu Y, Klionsky L, Zhang TJ, Immke D, Wang J, Zhu D, Vanderah TW, Porreca F, Doherty EM, Norman MH, Wild KD, Bannon AW, Louis JC, Treanor JJ (2005b) AMG 9810 [(E)-3-(4-t-butylphenyl)$\mathrm{N}$-(2,3-dihydrobenzo[b] [1,4] dioxin-6-yl)acrylamide], a novel vanilloid receptor 1 (TRPV1) antagonist with antihyperalgesic properties. J Pharmacol Exp Ther 313:474-484.

Ghilardi JR, Rohrich H, Lindsay TH, Sevcik MA, Schwei MJ, Kubota K, Halvorson KG, Poblete J, Chaplan SR, Dubin AE, Carruthers NI, Swanson D, Kuskowski M, Flores CM, Julius D, Mantyh PW (2005) Selective blockade of the capsaicin receptor TRPV1 attenuates bone cancer pain. J Neurosci 25:3126-3131.

Holzer P (1991) Capsaicin: cellular targets, mechanisms of action, and selectivity for thin sensory neurons. Pharmacol Rev 43:143-201.

Holzer P (2004) TRPV1 and the gut: from a tasty receptor for a painful vanilloid to a key player in hyperalgesia. Eur J Pharmacol 500:231-241.

Honore P, Wismer CT, Mikusa J, Zhu CZ, Zhong C, Gauvin DM, Gomtsyan A, El Kouhen R, Lee CH, Marsh K, Sullivan JP, Faltynek CR, Jarvis MF (2005) A-425619 [1-isoquinolin-5-yl-3-(4-trifluoromethyl-benzyl)urea], a novel transient receptor potential type V1 receptor antagonist, relieves pathophysiological pain associated with inflammation and tissue injury in rats. J Pharmacol Exp Ther 314:410-421.

Hori T (1984) Capsaicin and central control of thermoregulation. Pharmacol Ther 26:389-416.

Hori T, Shibata M, Kiyohara T, Nakashima T, Asami A (1988) Responses of anterior hypothalamic-preoptic thermosensitive neurons to locally applied capsaicin. Neuropharmacology 27:135-142.

Iida T, Shimizu I, Nealen ML, Campbell A, Caterina M (2005) Attenuated fever response in mice lacking TRPV1. Neurosci Lett 378:28-33.

Jakab B, Helyes Z, Varga A, Bolcskei K, Szabo A, Sandor K, Elekes K, Borzsei R, Keszthelyi D, Pinter E, Petho G, Nemeth J, Szolcsanyi J (2005) Pharmacological characterization of the TRPV1 receptor antagonist JYL1421 (SC0030) in vitro and in vivo in the rat. Eur J Pharmacol 517:35-44.

Jancso-Gabor A, Szolcsanyi J, Jancso N (1970a) Irreversible impairment of 
thermoregulation induced by capsaicin and similar pungent substances in rats and guinea-pigs. J Physiol (Lond) 206:495-507.

Jancso-Gabor A, Szolcsanyi J, Jancso N (1970b) Stimulation and desensitization of the hypothalamic heat-sensitive structures by capsaicin in rats. J Physiol (Lond) 208:449-459.

Jhamandas K, Yaksh TL, Harty G, Szolcsanyi J, Go VL (1984) Action of intrathecal capsaicin and its structural analogues on the content and release of spinal substance P: selectivity of action and relationship to analgesia. Brain Res 306:215-225.

Ji RR, Samad TA, Jin SX, Schmoll R, Woolf CJ (2002) p38 MAPK activation by NGF in primary sensory neurons after inflammation increases TRPV1 levels and maintains heat hyperalgesia. Neuron 36:57-68.

Jordt SE, Julius D (2002) Molecular basis for species-specific sensitivity to "hot" chili peppers. Cell 108:421-430.

Jordt SE, McKemy DD, Julius D (2003) Lessons from peppers and peppermint: the molecular logic of thermosensation. Curr Opin Neurobiol 13:487-492.

Keeble J, Russell F, Curtis B, Starr A, Pinter E, Brain SD (2005) Involvement of transient receptor potential vanilloid 1 in the vascular and hyperalgesic components of joint inflammation. Arthritis Rheum 52:3248-3256.

Lee H, Iida T, Mizuno A, Suzuki M, Caterina MJ (2005) Altered thermal selection behavior in mice lacking transient receptor potential vanilloid 4 . J Neurosci 25:1304-1310.

Moqrich A, Hwang SW, Earley TJ, Petrus MJ, Murray AN, Spencer KS, Andahazy M, Story GM, Patapoutian A (2005) Impaired thermosensation in mice lacking TRPV3, a heat and camphor sensor in the skin. Science 307:1468-1472.

Ognyanov VI, Balan C, Bannon AW, Bo Y, Dominguez C, Fotsch C, Gore VK, Klionsky L, Ma VV, Qian YX, Tamir R, Wang X, Xi N, Xu S, Zhu D, Gavva NR, Treanor JJ, Norman MH (2006) Design of potent, orally available antagonists of the transient receptor potential vanilloid 1. Structureactivity relationships of 2-piperazin-1-yl-1H-benzimidazoles. J Med Chem 49:3719-3742.

Patapoutian A, Peier AM, Story GM, Viswanath V (2003) ThermoTRP channels and beyond: mechanisms of temperature sensation. Nat Rev Neurosci 4:529-539.

Pomonis JD, Harrison JE, Mark L, Bristol DR, Valenzano KJ, Walker K (2003) N-(4-Tertiarybutylphenyl)-4-(3-cholorphyridin-2-

yl)tetrahydropyrazine-1(2H)-carbox-amide (BCTC), a novel, orally effective vanilloid receptor 1 antagonist with analgesic properties: II. in vivo characterization in rat models of inflammatory and neuropathic pain. J Pharmacol Exp Ther 306:387-393.

Premkumar LS, Ahern GP (2000) Induction of vanilloid receptor channel activity by protein kinase C. Nature 408:985-990.

Rabe LS, Buck SH, Moreno L, Burks TF, Dafny N (1980) Neurophysiological and thermoregulatory effects of capsaicin. Brain Res Bull 5:755-758.

Romanovsky AA (2007) Thermoregulation: some concepts have changed. Functional architecture of the thermoregulatory system. Am J Physiol Regul Integr Comp Physiol 292:R37-R46.

Seabrook GR, Sutton KG, Jarolimek W, Hollingworth GJ, Teague S, Webb J, Clark N, Boyce S, Kerby J, Ali Z, Chou M, Middleton R, Kaczorowski G, Jones AB (2002) Functional properties of the high-affinity TRPV1
(VR1) vanilloid receptor antagonist (4-hydroxy-5-iodo-3methoxyphenylacetate ester) iodo-resiniferatoxin. J Pharmacol Exp Ther 303:1052-1060.

Suh YG, Lee YS, Min KH, Park OH, Seung HS, Kim HD, Park HG, Choi J, Lee J, Kang SW, Oh UT, Koo JY, Joo YH, Kim SY, Kim JK, Park YH (2003) Novel non-vanilloid VR1 antagonist of high analgesic effects and its structural requirement for VR1 antagonistic effects. Bioorg Med Chem Lett 13:4389-4393.

Swanson DM, Dubin AE, Shah C, Nasser N, Chang L, Dax SL, Jetter M, Breitenbucher JG, Liu C, Mazur C, Lord B, Gonzales L, Hoey K, Rizzolio M, Bogenstaetter M, Codd EE, Lee DH, Zhang SP, Chaplan SR, Carruthers NI (2005) Identification and biological evaluation of 4-(3trifluoromethylpyridin-2-yl)piperazine-1-carboxylic acid (5-trifluoromethylpyridin-2-yl)amide, a high affinity TRPV1 (VR1) vanilloid receptor antagonist. J Med Chem 48:1857-1872.

Szallasi A, Appendino G (2004) Vanilloid receptor TRPV1 antagonists as the next generation of painkillers. Are we putting the cart before the horse? J Med Chem 47:2717-2723.

Szallasi A, Blumberg PM (1999) Vanilloid (capsaicin) receptors and mechanisms. Pharmacol Rev 51:159-212.

Szelenyi Z, Hummel Z, Szolcsanyi J, Davis JB (2004) Daily body temperature rhythm and heat tolerance in TRPV1 knockout and capsaicin pretreated mice. Eur J Neurosci 19:1421-1424.

Szolcsanyi J (2004) Forty years in capsaicin research for sensory pharmacology and physiology. Neuropeptides 38:377-384.

Szolcsanyi J, Joo F, Jancso-Gabor A (1971) Mitochondrial changes in preoptic neurons after capsaicin desensitization of the hypothalamic thermodetectors in rats. Nature 229:116-117.

Tominaga M, Caterina MJ, Malmberg AB, Rosen TA, Gilbert H, Skinner K, Raumann BE, Basbaum AI, Julius D (1998) The cloned capsaicin receptor integrates multiple pain-producing stimuli. Neuron 21:531-543.

Toth A, Boczan J, Kedei N, Lizanecz E, Bagi Z, Papp Z, Edes I, Csiba L, Blumberg PM (2005) Expression and distribution of vanilloid receptor 1 (TRPV1) in the adult rat brain. Brain Res Mol Brain Res 135:162-168.

Valenzano KJ, Grant ER, Wu G, Hachicha M, Schmid L, Tafesse L, Sun Q, Rotshteyn Y, Francis J, Limberis J, Malik S, Whittemore ER, Hodges D (2003) N-(4-tertiarybutylphenyl)-4-(3-chloropyridin-2yl)tetrahydropyrazine-1(2H)-carbox-amide (BCTC), a novel, orally effective vanilloid receptor 1 antagonist with analgesic properties: I. in vitro characterization and pharmacokinetic properties. J Pharmacol Exp Ther 306:377-386.

Van Der Stelt M, Di Marzo V (2004) Endovanilloids. Putative endogenous ligands of transient receptor potential vanilloid 1 channels. Eur J Biochem 271:1827-1834

Wang Y, Toth A, Tran R, Szabo T, Welter JD, Blumberg PM, Lee J, Kang SU, Lim JO (2003) High-affinity partial agonists of the vanilloid receptor. Mol Pharmacol 64:325-333.

Xi N, Bo Y, Doherty EM, Fotsch C, Gavva NR, Han N, Hungate RW, Klionsky L, Liu Q, Tamir R, Xu S, Treanor JJ, Norman MH (2005) Synthesis and evaluation of thiazole carboxamides as vanilloid receptor 1 (TRPV1) antagonists. Bioorg Med Chem Lett 15:5211-5217. 